ISBN 978-93-84468-75-0

2016 International Conference on Business, Human Resources and Education

(ICBHRE-16)

Oct.11-12, 2016 at Dubai (UAE)

\title{
Integrating Digital Education Resources based on National Content into English Teaching Classes
}

\author{
Jannat Sagimbayeva, and GulzhakhanTazhitova \\ L.N. Gumilyov Eurasian National University (Astana, Kazakhstan)
}

\begin{abstract}
Incorporating new information technologies in teaching English is one of the most important aspects of enhancement and optimization of educational process, enrichment of the methodical means and techniques allowing diversifying forms of work in order to make classes interesting and memorable. The paper demonstrates the importance of integrating digital education resources based on national content as they help students to cognize culture, social life, politics and economics of the country. Moreover, digital education resources based on national content allow practicing various types of speech activity and combining them in various combinations; help to realize linguistic phenomena, form communication skills. The conducted experiment showed positive results since digital education resources create favorable conditions for successful performance of each student, and using national content in creating digital resources contribute increase learning efficiency of a foreign language.
\end{abstract}

Keywords: teaching technologies, languages, digital education resources, national content, learning efficiency.

\section{Introduction}

Currently, Kazakhstan education pays great attention to the issues of learning foreign languages. The content and programs of learning foreign languages are changing and renewing. The informatization in teaching foreign languages is one of the key purposes of education. Within this target a number of projects on creation of the digital education resources (DER) based on national content providing implementation of educational programs is carried out. The programs directed to the solution of current objectives of informatization of education including development of educational information space, development of digital educational resources based on national content, creation of system of educational portals are realized.

The Digital Educational Resources (DER) is an information source which contains graphic, text, digital, speech, and musical information, directed to achievement of educational problems of educational process. DER - the component of process of all activities of the modern teacher promoting optimization and integration of educational and extracurricular activities. This educational resource can be presented on CD, DVD or any other electronic medium, and also is placed on the Internet.

DER can solve the following problems:

- to introduce a new training material;

- to revise and consolidate the vocabulary;

- to carry out intermediate and total control of knowledge;

- to create game educational situations;

- to help students to be prepared for the examination. 
DERs containing national content help to avoid monotony of the class. Language learnt through national content and information perceived in various ways (through video, graphics, a sound) is acquired better and acquired in memory longer. Staginess, lesson material brightness in combination with other methodical receptions do homework unusual, memorable, bright, increases motivation of students to studying of English, allows realizing an individual approach in training.

There have been a number of studies of using DER in English classes. The production of digital learning resources occurs in a variety of settings. The work of several researchers A.J.Romiszowski, 1986, B.N.Flagg, 1990, J.R. Hill, 2001, A.E.Mhouti, 2013 devoted their works to conditions, methods, criteria and evaluation of digital learning resources. It should be noted that in the Republic of Kazakhstan the Kazakh scientist G.K.Nurgalyeva dealt with problems of graphical preparation of DER. E.V.Mukovnikova emphasized that use of DER in English classes excludes such opportunity: the computer doesn't abuse the student for failure, therefore use of DER doesn't show negative emotions, corrects errors and praises for successful performed work. Incorporating DER in educational activities help to overcome difficulties in training and self-affirmation of students. However, none of these studies consider DER based on national content and its importance in teaching. The purpose of this study is to demonstrate the importance of integrating digital education resources based on national content. Use of digital education resources containing national content makes the learning of foreign languages more effective and productive. The conducted experiment showed positive results since digital education resources create favorable conditions for successful performance of each student, and using national content in creating digital resources contribute increase learning efficiency of a foreign language.

\section{Methodology}

To carry out our study, which aims to demonstrate the importance of using DER based on national content the experiment was conducted. One group of 15 students and another one of 16 students majoring in Economics of Eurasian National University in Astana participated in this small - research project. Most of the students were females; their ages ranged from 17 to 19 years old. They attended the course "General English" three hours a week. Most students had studied at public schools where English was taught twice a week. One group was taught on the basis of regular program with traditional methods, another one was offered DER based on national component.

\section{Data Collection and Analysis}

The aim of this experiment was to use DER based on national content to identify the effectiveness of its use. During one semester students of the second group were supposed to work on DER based on national component in English classes. The aims of DER based on national component are: implementation of the humanistic and personal oriented approach to training, strengthening of motivation of cognitive activity of students, development of critical thinking, increase in efficiency of assessment, control and monitoring, results of educational activities, development of figurative, theoretical, logical thinking, development of creative and creative capabilities of students, development of educational potential of students, development of functional literacy, creation of conditions for favorable emotional perception.

The main feature of the DER was that its content devoted to the national component. The content of the course is presented by the sequence of interconnected DER on separate 15 topics. Each DER includes three components: theoretical part, interactive part (tasks) and test part (test tasks).

The theoretical part consisted of grammar and the material based on national component on the following topics such as: Family, Great Figures, Education, Holidays, etc. Students were offered the materials about famous people, family, education, customs and traditions of Kazakhstan. For example: 


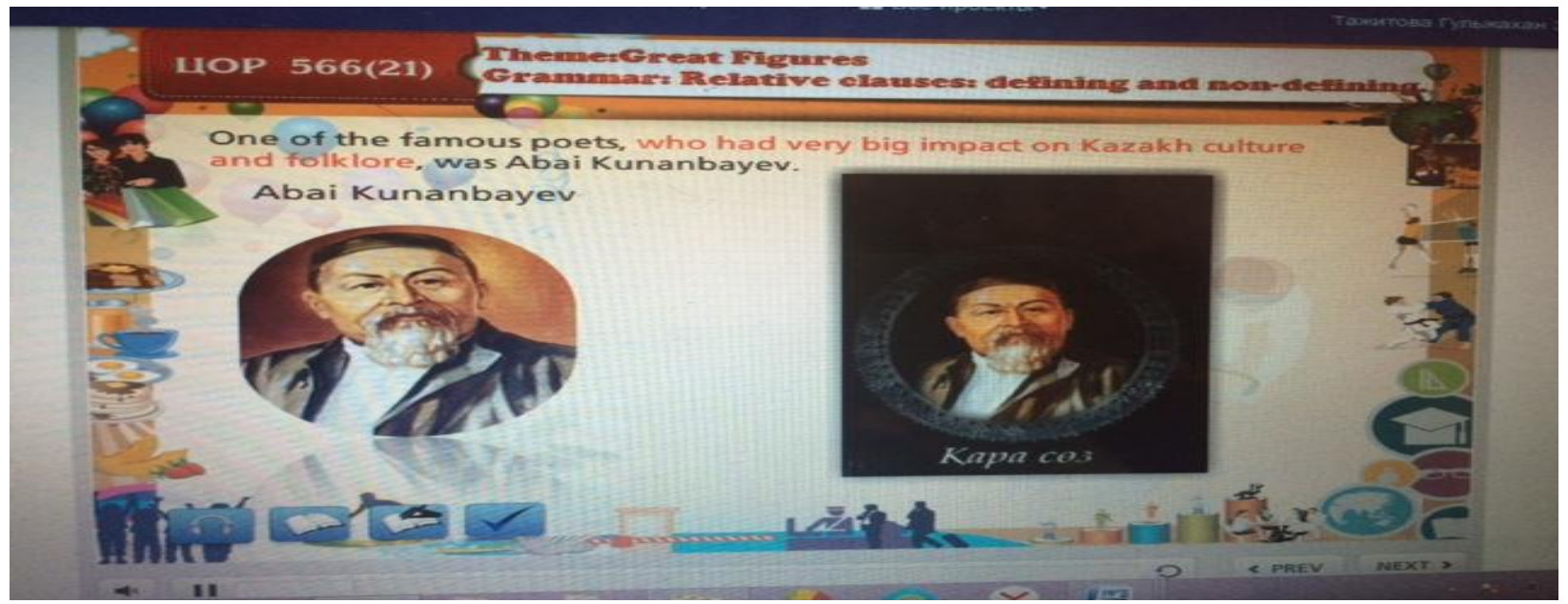

Fig.1 Great Figures

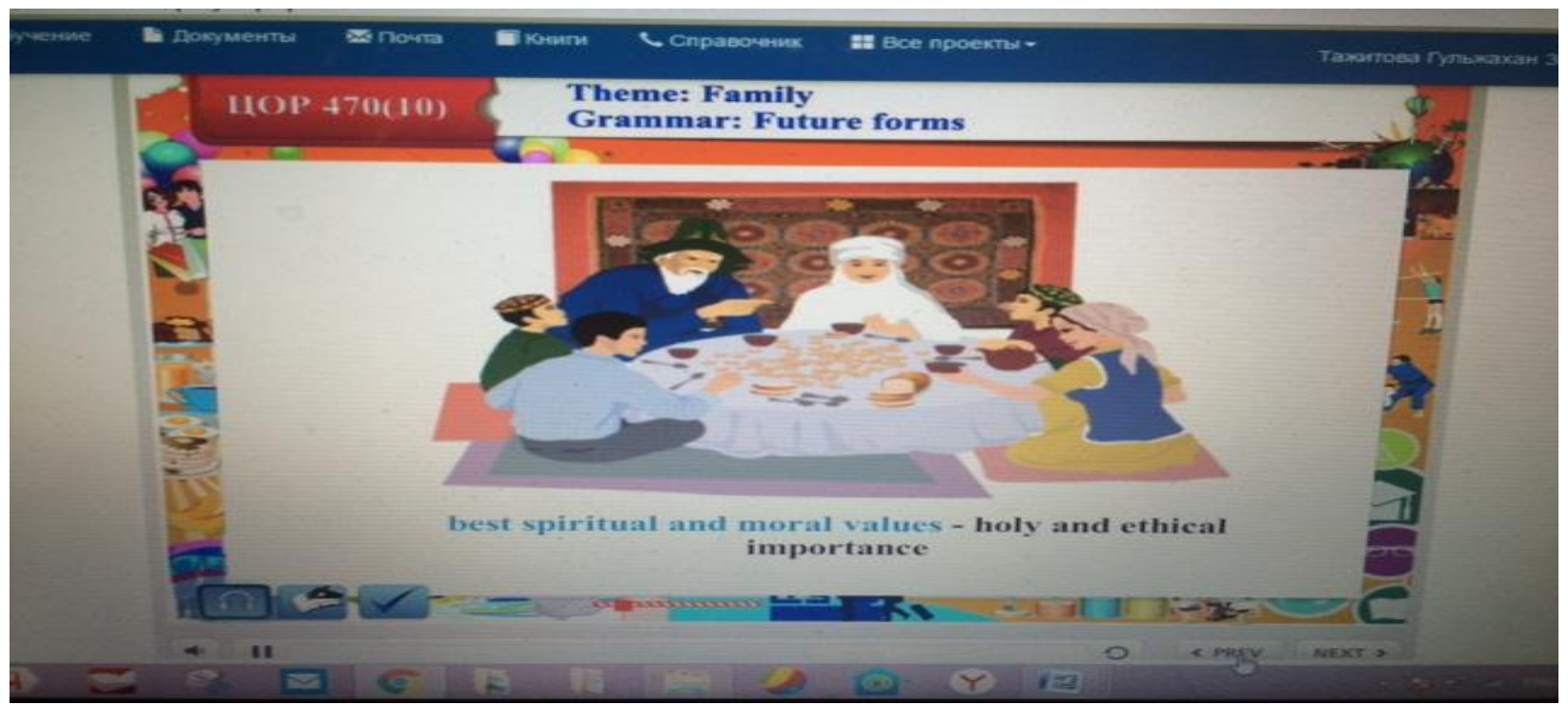

Fig. 2 Family

On the basis of national material it is possible to model quite real communicative situations: topics about the native land, about its great people, about family values and others allow increase not only efficiency of all aspects of education - moral, civil, esthetic, but also considerably increase motivation of students to a learning of foreign language.

During the second part of the DER program students were supposed to fulfill the tasks to consolidate the grammar and material based on national content. For example:

Match the words and word combinations with their definitions; Complete the table: Choose and write the words related to the text; Drag the words to the correct definitions and others.

The third part of the program was devoted to checking the obtained knowledge where students had to do test tasks.

\section{Findings and Discussion}

During the conducted classes students got a lot of information about national traditions, family values, great people, etc in English language through DER and fulfilled various exercises for consolidation of the obtained knowledge. From the received results it can be noted that most students could do tests successfully. Learning the material based on national context through DER was interesting and beneficial for them. Teaching a foreign language is not only introduction of the world of foreign-language culture, but it is also understanding of their 
native culture that is important for formation of the identity of students forming their outlook and cultural development.

For this reason, use of a national component in foreign language classes becomes more and more urgent. Studying of native culture is a necessary component of training process of foreign languages, because it becomes a key to understanding of foreign culture, promotes forming of such qualities of the personality as patriotism and tolerance, independence in acquisition of knowledge that is an important educational factor in the conditions of modern modernization of education. Integrating national component into DER contributes to state material more intelligibly, for smaller time, with big understanding; to find the main and additional materials for classes or an elective course; to save time for speech practice; to organize individual and group work with a class, to simplify monitoring educational activity of students, to increase their motivation, to involve students in creative process, to increase speed and reliability of assimilation of knowledge.

Use of DER allows to improve efficiency and quality of education; to be guided by the modern purposes of training; to increase motivation of students to training; to use the interconnected training in different types of activities; to consider regional aspect; to make lessons emotional and memorable; to realize individual approach; to increase independence of students; to change nature of interaction of the teacher and the students; to objectively estimate knowledge of students; to increase quality of presentation; to facilitate of the teacher's work.

Moreover, use of DER allows in case of the minimum costs of time to create visual aids and as a result to increase presentation and fascination of the class, to visualize a lesson by means of multimedia elements which, unlike posters, can be adjusted as required. Furthermore, important value has also the fact that such visual aids are stored in electronic form and it doesn't need lot of place in laboratories. Besides, classes can be given not only in specially equipped class, but also in any other room in which it is possible to develop the screen and the video projective equipment with the computer (laptop).

When using DER we rely on the basic scientific and methodical principles: communicativeness, presentation, individualization. Besides, the interactive control tests and exercises which are a part of DER with system of reactions to the wrong answer (hints, leading questions, hyperlinks to a help part of benefits, individual recommendations) allow to analyze the level of development of various subjects in general.

DER help students:

- to develop thinking system, to learn to analyze, compare and generalize the facts;

- to master skills of work with big arrays of information, information search and its competent use;

- to study, consolidate and review independently;

- to purchase skills of work with the computer;

- to understand and memorize the material better.

As research studies show, the fear of a mistake is one of the most powerful barriers on the way of formation of creative capabilities. Therefore use of DER English classes exclude such opportunity: the computer doesn't abuse the student for failure and doesn't show negative emotions, and corrects errors and praises for successfully performed work, thereby without breaking personal development of the student and stimulating motivation of studying of English. Use of DER in educational and extracurricular activities helps to overcome difficulties in training and self-affirmation of students as allows them to open the opportunities and capabilities. Through DER students can develop the creative and informative activity, realize the best personal qualities, i.e. show those capabilities which often remain unclaimed in classes. All these create a favorable background for achievement of success that, in turn, positively influences also educational activities. 


\section{Conclusion}

In conclusion, it would be desirable to note that full implementation of DER in educational process allows to supplement and combine new techniques with traditional methods of teaching, use information technologies, to apply individual approach, to develop linguistic capabilities of students and to objectively estimate quality of knowledge of each student. The innovative educational environment represents favorable conditions which provide the graduate with competitive advantages on the basis of provision of the advanced knowledge and further maintenance it during all life. The teacher becomes the consultant, the mentor whose main task to teach the student to algorithmic thinking: to independent goal setting and tasks; to the choice of effective tools of their decision; to a quality evaluation of own work; to ability to work with information; to requirement and skills of self-education; capabilities to work in team. The tendency of active implementation of DER changes methods and forms of higher school.

\section{References}

[1] A.J.Romiszowski, "Developing Auto -Instructural materials: from Programmed Texts to CAL and Interactive Video. New York, Nicholas Publishing Company, 1986.

[2] B.N.Flag, Formative Evaluation for Educational Technologies. Hillsdale, NJ:Lawrence Erlbaum, 1990.

[3] J.R.Hill, M.J.Hannafin, Teaching and learning in digital environments: The resurgence of resource based learning, Educational Technology Research and Development, Volume 10, Issue 2, pp. 44-45, 2001. http://dx.doi.org/10.1007/bf02504914

[4] A.E.Mhouti, A.Nasseh, M.Erradi, "How to evaluate the quality learning resources?" International Journal of Computer Science Research and Application, Vol.03, Issue.03 pp.27 -36, 2013

[5] G.K.Nurgalyeva, "E -learning of new paradigm and condition of mass education", National Centre of informatization, 2012.

[6] E.V.Mukovnikova, "Effective use of Digital education Resources in English classes", The first September, 2015

[7] J.E.Sagimbayeva, A.M.Mukhtarkhanova, G.Z.Moldahmetova, G.Z.Tazhitova, Zh.Kuzar "Digital Education Resources", 2015. Available: www.moodle.kz 